\title{
What if Dutch investors started worrying about flood risk? Implications for disaster risk reduction
}

\author{
Trond G. Husby • Reinhard Mechler • \\ Brenden Jongman
}

Received: 15 March 2014 / Accepted: 2 February 2015/Published online: 3 March 2015

(c) The Author(s) 2015. This article is published with open access at Springerlink.com

\begin{abstract}
Increasingly, roles and responsibilities of the public sector in flood risk management are receiving attention in research and policy. Part of the debate suggests that allocating risk to the private sector increases efficiency as it promotes individual adaptation, thereby reducing the impact if a disaster occurs. In this paper, we analyse the macroeconomic effects as risk-averse investors take flood risk into account in their investment decisions. Our case study is the large Rotterdam area in the Netherlands. Using a spatial computable general equilibrium model, we find that the decrease in investments in risky areas leads to a reduction in capital and production in the large Rotterdam area, leading to a reduction in potential monetary disaster losses, but not to a reduction in population. The reallocation of risk reduces the long-term impacts from a flood on government tax revenues, but it also leads to welfare losses among households residing in risky regions.
\end{abstract}

Editor: Christopher Reyer.

T. G. Husby · B. Jongman

Institute for Environmental Studies (IVM), VU University

Amsterdam, De Boelelaan 1087, 1081 HV Amsterdam,

The Netherlands

e-mail: brenden.jongman@vu.nl

T. G. Husby $(\bowtie)$

TNO, Strategy \& Policy, Van Mourik Broekmanweg 6,

2628 XE Delft, The Netherlands

e-mail: trond.husby@vu.nl

R. Mechler

Risk, Policy and Vulnerability Program, International Institute for Applied Systems Analysis (IIASA), Schlossplatz 1,

2361 Laxenburg, Austria

e-mail: mechler@iiasa.ac.at
Keywords Flood risk - Natural disasters - Investment under risk and uncertainty $\cdot$ Spatial computable general equilibrium

\section{Introduction}

The flooding of the Danube in the summer of 2013 and the winter floods in the UK in January 2014 are just two of many large-scale flood disasters which recently have hit modern industrialised economies. Such disasters cause large direct economic losses as well as ripple effects, leading to economic losses beyond the location directly affected by the disaster (Hallegatte 2008). The prospects of increasing future risk due to socio-economic developments and climate change have drawn attention to the allocation of risk across and within countries, and to the allocation of risk between the public and private sector (Botzen 2013; Jongman et al. 2014; Mechler et al. 2014; Linnerooth-Bayer and Hochrainer-Stigler 2014).

There is a wide continuum of sharing risk and responsibilities in flood risk management across countries (Aakre et al. 2010). One of the most extreme cases in terms of public sector responsibilities is the Netherlands. The country is one of the most flood prone in the world, with more than $50 \%$ of its land exposed to flooding (de Moel et al. 2011). Traditionally, the Dutch government has responded to the threat of water through a tax-payer funded system of extremely high safety standards combined with a public ex-post compensation scheme (Aerts and Botzen 2011). However, the traditional approach has not led to a decrease in exposure (Husby et al. 2014). For example, due to the rapid economic growth in the economically important Randstad region, a major flood event here would have major economic consequences for the country as a whole (Bouwer and Vellinga 2007). 
A number of near-miss flood events, leading to mass evacuation of population at risk, have led to a rethinking of the strategy, including a shift in focus towards reducing the consequences should a flood happen (Kabat et al. 2005). Adaptive measures in spatial development, such as new building codes, elevation of buildings or even relocation, have been introduced as part of a new strategy (Min I \& M 2009 , 2014). Crucially, the new proposals imply a partial reallocation of risk, shifting some of the responsibility for mitigating flood damage from the public to the private sector. Current research on flood risk management in the Netherlands revolves around the suitability of these types of measures for the Dutch situation (Veraart et al. 2014).

A growing body of research argues that it is plausible that private investors could take flood risk into account in their investment decisions, decreasing the capital stock in risky areas (Kousky et al. 2006; Balvers et al. 2009; Hallegatte 2011; Baker and Bloom 2013; Barro 2013). Despite substantial damages in case of a flood and uncertainties regarding compensation of losses, risk perceptions in the Netherlands are currently low (Terpstra et al. 2009; Botzen and van den Bergh 2012). The strong public concern elicited by recent events (Daniel et al. 2009) suggests that the Dutch are highly averse towards flood risk. Little is known about the relative contribution from factors behind changes in investment behaviour, or about the ensuing macroeconomic effects. This paper takes on the challenge, analysing the thought-experiment what if investors started worrying about flood risk in the Netherlands.

The aim of this paper is to investigate the long-term economic and welfare effects if investors in the Netherlands took flood risk into account. We assume that risk is directly relevant for capital investments but only indirectly relevant for households' decisions. We propose a macroeconomic model where investment decisions are based on a mean-semivariance approach (Markowitz 1959). In our model, risk-averse investors base their investment decisions on the probability of flooding and on the capital damage should a flood occur. Simulations of increases in probability and capital damage allow us to investigate the conditions necessary to trigger behavioural responses from investors.

\section{Case study: the large Rotterdam area}

The large Rotterdam area is used as a case study. It is a densely populated region which contains the second biggest city in the Netherlands and one of Europe's largest ports. Its geographical location on the delta of two major rivers makes it highly vulnerable to flooding, and it is one of the few regions in the Netherlands where adaptive measures in spatial development are being proposed as a response to future increases in flood risk (Min I \& M 2009).

As indicated in Fig. 1, the large Rotterdam area consists of several dike-rings with varying safety standards. Safety standards require that the height of the dikes meet a design level expressed as exceedance probabilities (the probability that the water level exceeds the top of the dike) or as return periods (exceedance probability and return period will be used interchangeably throughout the text). Return periods vary between $1 / 10,000$ and $1 / 4000$ in areas susceptible to intrusion from the sea and between 1/2000 and 1/1250 for areas susceptible to river flooding. Although most residential and industrial areas are protected by dikes, there is considerable variation in the probability of flooding within the region. For example, built-up areas between the river and the dike are subject to higher flood probabilities than areas behind the dike (Moel et al. 2014). In addition, it is likely that the actual probability of flooding in some areas differs substantially from the safety standards. Differences in the spatial concentration of economic activity as well as differences in inundation depths mean that there are relatively large sectoral differences in direct damage between dike-rings.

\section{Methodology}

In the economic disaster literature, it is common to distinguish between direct and indirect effects of flood disasters [see, e.g. Rose (2004) or Merz et al. (2010)]. Direct effects cover the immediate losses resulting from a certain level of inundation in a particular area, while indirect effects are conceptualised as business interruptions, for example, when damage to infrastructure interrupts supply lines resulting in scarcity of intermediate and final goods. Estimating indirect and long-term effects of disasters is particularly challenging due to the complex interlinkages between different sectors and agents within the economy. Several authors have used computable general equilibrium (CGE) models to analyse indirect and long-run effects [see Okuyama (2008) for a review]. These models represent an economy as systems of equations, where agents in the economy react to price changes determined by market equilibria. Income and spending are modelled as circular flows interconnecting all sectors and regions of the economy. One major strength of these models is their ability to incorporate sectoral interlinkages and economic behaviour of agents (Mechler 2013). Another strength with this model type is that direct effects are treated as inputs (direct damage), while indirect effects are model outcomes (general equilibrium effects), thereby avoiding double counting losses. 


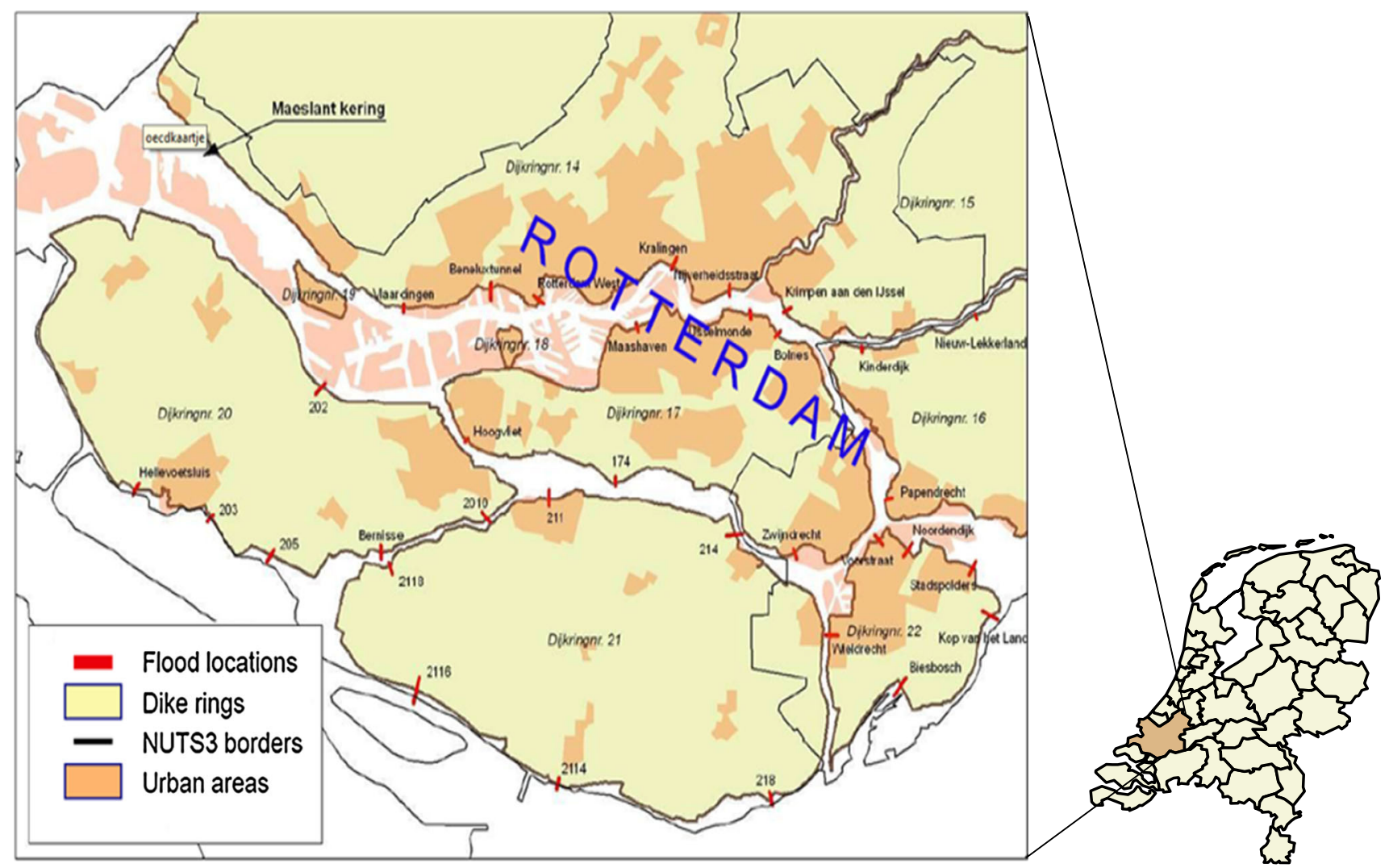

Fig. 1 Large Rotterdam area and NUTS-3 regions in the Netherlands. Dike breaches from the flood scenarios in Jonkhoff et al. (2008) are indicated in the left part of the figure

\section{RAEM: general description}

The model used in this paper-RAEM (regional computable general equilibrium model)—is a recursively dynamic spatial computable general equilibrium (SCGE) model. The model was initially developed for cost-benefit analyses of transport infrastructure projects in the Netherlands (Thissen 2005; Ivanova et al. 2007). It distinguishes 40 regions, corresponding to Dutch NUTS-3 level as defined by Eurostat, and it spans 15 production sectors. Agents in RAEM are firms, households, a federal government, an external trade sector and an investment agent. RAEM belongs to the New Economic Geography (NEG) school-a theoretical direction which focuses on how the spatial pattern in the location of economic production is an outcome of agglomeration and dispersion forces (Krugman 1991; Fujita and Thisse 1996). A central assumption in NEG is that firms benefit from a geographical location due to the presence of increasing returns (monopolistic competition). Households, in turn, gain utility from the variety of products available in one region. The NEG features thus allow RAEM to capture feedback effects between production and households' location decisions. These feedback effects result in clustering of economic activity and population. The nonlinear mathematical formulation and increasing returns to scale imply that a small change in a certain parameter does not necessarily lead to small changes in the same direction across all sectors.

In each sector, a representative firm uses capital, intermediate goods and labour as inputs to production. Available capital in each period is defined by the (depreciated) amount of capital stock from the previous period and new investments. Firms determine their level of production and level of inputs by minimising costs for given prices of production inputs. A share of the production is exported to other regions, and a share is destined for demand within the region. The total supply of goods within one region consists of production by firms within the region and imports and is in equilibrium equal to total domestic demand. Total domestic demand for a good is the sum of intermediate demand and final demands. Intermediate demand depends on the demand from the productive sectors. Final demand is the sum of government demand, investment demand and household demand for consumption goods. Household demand for consumption goods is determined by maximising utility given a budget constraint. The consumption 
budget is spent on consumption goods and taxes, while income is a sum of labour and capital income. The utility maximisation procedure gives rise to a level of regional equilibrium welfare. Households decide where to locate by comparing utility across regions, locating in the region where it can obtain the highest level. The ensuing labour migration feeds back into firms' production decisions, both in the form of labour supply and in the form of final demand for goods.

RAEM: recursive dynamics and capital accumulation

The connection between different time periods in RAEM is modelled according to a recursively dynamic formulation. The model consists of a sequence of temporary equilibria where the equilibria are connected to each other through capital accumulation over time. Capital $K_{\mathrm{Si}, i, t}$ in sector $\mathrm{Si}$ in region $i$ evolves due to capital depreciation $\delta$ and sectorand region-specific investment $\mathrm{INV}_{\mathrm{Si}, i, t}$. Parameters and initial values of variables in RAEM are calculated using a social accounting matrix for the Netherlands from the year 2006. Frequency is yearly, and we analyse the period $t=2007, \ldots, 2025$.

$K_{\mathrm{Si}, i, t+1}=K_{\mathrm{Si}, i, t}\left(1-\delta_{\mathrm{Si}, i}\right)+\mathrm{INV}_{\mathrm{Si}, i, t}$

Investment in period $t$ is based on expected capital growth in $t+1$, which again is a general equilibrium outcome in period $t$. Determining capital stock in the next period, $K_{\mathrm{Si}, i, t+1}$, as a function of capital growth $f\left(\alpha \mathrm{ROR}_{\mathrm{Si}, i, t}\right)$, investments in the original formulation of RAEM is summarised by the following equations:

$$
\begin{aligned}
\operatorname{INV}_{\mathrm{Si}, i, t} & =K_{\mathrm{Si}, i, t}\left[f\left(\alpha \mathrm{ROR}_{\mathrm{Si}, i, t}\right)+\left(1-\delta_{\mathrm{Si}, i}\right)\right] \\
\alpha \mathrm{ROR}_{\mathrm{Si}, i, t} & =\exp \left(\mathrm{ROR}_{\mathrm{Si}, i, t}-\mathrm{ROR}_{\mathrm{Si}, i, t}^{0}\right) \\
\operatorname{ROR}_{\mathrm{Si}, i, t} & =-1+\frac{\frac{\mathrm{RK}_{\mathrm{S}, i, t}}{\mathrm{PI}_{\mathrm{Si}, i, t}}+1-\delta_{\mathrm{Si}, i}}{1+\frac{\mathrm{RGD}_{t}}{\mathrm{GDPDE}_{t}}}
\end{aligned}
$$

The variables/parameters are: $\mathrm{ROR}_{\mathrm{Si}, i, t}$ : expected rate of return to capital investments; $\mathrm{ROR}_{\mathrm{Si}, i}^{0}$ : baseline expected rate of return; $\alpha \mathrm{ROR}_{\mathrm{Si}, i, t}$ : growth rate of the rate of return relative to baseline; $\mathrm{RK}_{\mathrm{Si}, i, t}$ : equilibrium capital growth, or equally, equilibrium rate of return; $\mathrm{PI}_{\mathrm{Si}, i, t}$ : price of investment; $\mathrm{RGD}_{t}$ : nominal interest rate; $\mathrm{GDPDEF}_{t}$ : GDP deflator. Using Eq. 1, we can write the region- and sectorspecific investment in terms of the capital stock and as a function of the expected capital growth above baseline growth (Eq. 3). The expected rate of return to capital $\mathrm{ROR}_{\mathrm{Si}, i, t}$ is determined as a function of the equilibrium rate of return $\mathrm{RK}_{\mathrm{Si}, i, t}$, the price of investment $\mathrm{PI}_{\mathrm{Si}, i, t}$ as well as the adaptive expectations regarding the interest rate.
We incorporate flood risk as a "correction factor" to the expected rate of return. The risk-adjusted expected rate return is modelled in line with the mean-variance approach, developed for risk analysis under downside risk (Markowitz 1959). In this approach, return to capital is based on the mean rate of return and volatility. Expected returns to capital investments are penalised with a risk premium $\mathrm{RP}_{\mathrm{Si}, i}$, determined by the semivariance $\operatorname{Var}\left(\mathrm{RK}_{\mathrm{Si}, i, t}\right)$ as well as relative risk-aversion $A$. The use of the semivariance captures the notion that only downside risk is relevant for investors. The parameter of relative riskaversion is set to $A=4$, indicating a high level of riskaversion (Mechler 2004). A flood which occurs with probability $p_{i}$ can reduce the rate of return with a certain amount $\Delta_{\mathrm{Si}, i} \cdot \Delta_{\mathrm{Si}, i}$ thus represents the percentage reduction in capital growth due to a flood. Defining $\mathrm{RK}_{\mathrm{Si}, i, t}^{*}$ as the risk-adjusted rate of return, we have

$$
\begin{gathered}
\mathrm{RK}_{\mathrm{Si}, i, t}^{*}=\left(1-p_{i}\right) \mathrm{RK}_{\mathrm{Si}, i, t}+p_{i}\left(\mathrm{RK}_{\mathrm{Si}, i, t}-\Delta_{\mathrm{Si}, i}\right) \\
-\frac{A}{2} \operatorname{Var}\left(\mathrm{RK}_{\mathrm{Si}, i, t}\right) \\
=\mathrm{RK}_{\mathrm{Si}, i, t}-p_{i} \Delta_{\mathrm{Si}, i}-\frac{A}{2} \operatorname{Var}\left(\mathrm{RK}_{\mathrm{Si}, i, t}\right)
\end{gathered}
$$

Using Eq. 4, we have

$$
\operatorname{ROR}_{\mathrm{Si}, i, t}=-1+\frac{\frac{\mathrm{RK}_{\mathrm{Si}, i, t}-p_{i} \Delta_{\mathrm{Si}, i}-\frac{A}{2} \operatorname{Var}\left(\mathrm{RK}_{\mathrm{Si}, i, t}\right)}{\mathrm{PI}_{\mathrm{Si}, i, t}}+1-\Delta_{\mathrm{Si}, i}}{1+\frac{\mathrm{RGD}_{t}}{\mathrm{GDPDEF}_{t}}}
$$

The yearly probability of flooding $p_{i}$ corresponds to the return period in each dike-ring. The true probability of flooding in each location is also influenced by other variables such as the probability of dike failure at water levels below the design standard. By using the return period, we thus assume that the safety level conveys the relevant information for the investment decision. $\Delta_{\mathrm{Si}, i}$ is calculated using the direct capital damage per sector from all the scenarios in Jonkhoff et al. (2008). To obtain NUTS3-level values for $p_{i}$ and $\Delta_{\mathrm{Si}, i}$ we sum over all dike-rings DR:

$p_{i} * \Delta_{\mathrm{Si}, i}=\sum_{\mathrm{DR}} p_{\mathrm{DR}, i} * \Delta_{\mathrm{DR}, \mathrm{Si}, i}$

\section{Data}

Values for $p_{i}$ and $\Delta_{\mathrm{Si}, i}$ are calculated from the data shown in Table 1 below. Data used for the calculation of the share of capital at risk, $\Delta_{\mathrm{Si}, i}$ are obtained from Jonkhoff et al. (2008). Jonkhoff et al. (2008) investigated both direct and indirect damages for a number of dike breaches in the region of Rotterdam (see Fig. 1). Total direct capital damages were calculated using the Dutch Damage and Casualty model HIS-SSM (Kok et al. 2005). This model combines 
Table 1 Return period of each dike-ring and the sectoral capital damage from the scenarios in Jonkhoff et al. (2008)

\begin{tabular}{llllllll}
\hline Dike ring & 14 & 15 & 16 & 17 & 20 & 21 & 22 \\
Probability & $1 / 10,000$ & $1 / 2000$ & $1 / 2000$ & $1 / 4000$ & $1 / 4000$ & $1 / 2000$ & $1 / 2000$ \\
\hline Sector & Damage & as & percentage of capital \\
Agriculture & 0.243 & 1.619 & 1.082 & 0.002 & 0.013 & 0.0250 & 0.068 \\
Mining and quarrying & 0.000 & 0.005 & 0.000 & 0.000 & 0.000 & 0.000 & 0.000 \\
Manufacturing & 0.135 & 0.080 & 0.130 & 0.004 & 0.001 & 0.004 & 0.103 \\
Electricity, gas and water supply & 0.213 & 0.0123 & 0.007 & 0.000 & 0.002 & 0.000 & 0.0218 \\
Construction & 0.006 & 0.009 & 0.010 & 0.0018 & 0.000 & 0.000 & 0.003 \\
Trade and repair consumer services & 0.097 & 0.032 & 0.039 & 0.002 & 0.001 & 0.001 & 0.035 \\
Hotels, restaurants and cafe & 0.211 & 0.069 & 0.084 & 0.004 & 0.001 & 0.004 & 0.077 \\
Transport & 0.064 & 0.092 & 0.109 & 0.005 & 0.001 & 0.002 & 0.031 \\
Storage and communication & 0.176 & 0.253 & 0.298 & 0.013 & 0.003 & 0.005 & 0.085 \\
Financial services & 0.165 & 0.099 & 0.067 & 0.001 & 0.001 & 0.001 & 0.043 \\
Business services, renting, real estate & 0.232 & 0.139 & 0.094 & 0.002 & 0.001 & 0.002 & 0.06 \\
Public administration & 0.405 & 0.140 & 0.174 & 0.008 & 0.002 & 0.001 & 0.197 \\
Education & 0.248 & 0.086 & 0.107 & 0.005 & 0.001 & 0.000 & 0.121 \\
Health and social work & 0.019 & 0.002 & 0.002 & 0.000 & 0.000 & 0.000 & 0.033 \\
Culture, sports and leisure & 0.011 & 0.001 & 0.001 & 0.000 & 0.000 & 0.000 & 0.018 \\
\hline
\end{tabular}

To illustrate how the modified investment behaviour affects disaster impacts, we simulate one of the dike breach scenarios from Jonkhoff et al. (2008). This scenario is dike-ring 14 in the region of Rotterdam, with breach points indicated in Fig. 1. We simulate a flood in $t=2016$, assuming, as the original study, a disruption period of two months. The flood is incorporated in RAEM as a partial reduction in available land, housing stock, capital stock and labour force. We interpret the reduction in labour force in RAEM as casualties.

\section{Results from the case study}

Ex-ante results: changes in labour force, production and unemployment

Figure 2 shows the impacts from the modified investment behaviour on labour force, production and unemployment in the region of Rotterdam under all scenarios until 2015. The shaded area indicates the range of impacts across scenarios on each variable. As shown by the green shaded area, their production declines by between 0 and $1.2 \%$ relative to baseline production. However, as shown by the red shaded area in the figure, labour force is reduced by between 0 and $0.1 \%$ relative to baseline labour. As shown by the blue shaded area, unemployment increases between 0 and $2 \%$ relative to baseline unemployment. Our results thus suggest that the reduction in production is about ten times higher than the reduction in labour force. The reduction in production is also accompanied by a relatively large increase in unemployment. As such, our results 


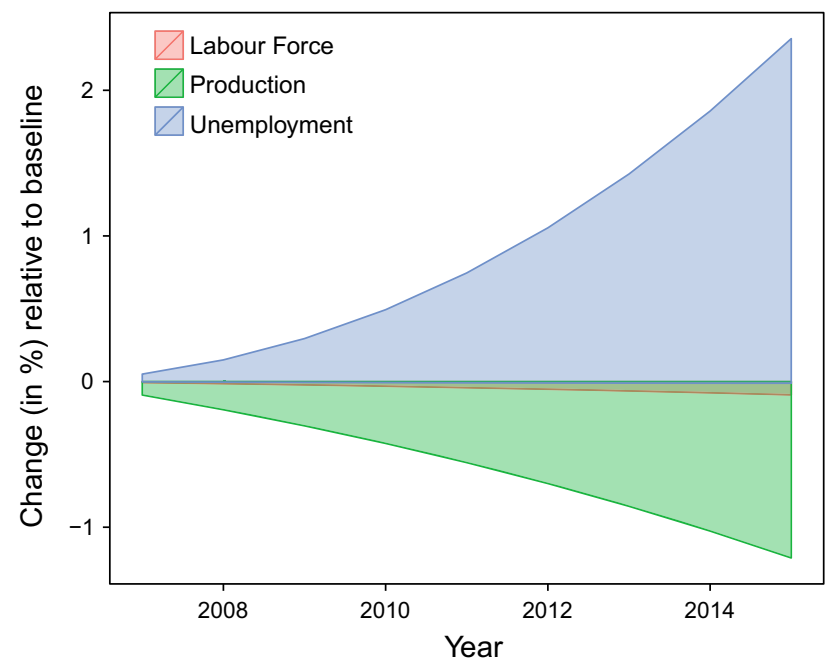

Fig. 2 Impacts on labour force, production and unemployment in the region of Rotterdam across all scenarios. The red shaded area shows changes in labour force, the green shaded area shows changes in production, and the blue shaded area shows changes in unemployment

suggest that the decrease in population is only minor despite the worsening of economic conditions.

\section{Direct, short-term effects: capital destruction and casualties}

In the previous subsection, we showed that the decrease in investments in the large Rotterdam areas led to lower production, but only to small reductions in labour force. The decrease in production leads to a reduction in capital stock, limiting the capital damage of a flood. However, there are only limited reductions in the number of casualties in case of a flood. This is illustrated in Tables 2 and 3 which show percentage reductions in direct capital damage and casualties in the scenarios relative to the original model without the modified investment behaviour. There are minor reductions in capital damage in all scenarios where $\Delta_{\mathrm{Si}, i}$ stays at its current level, while the damage in scenarios where $\Delta_{\mathrm{Si}, i}$ increases by a factor of 10 , direct damage is reduced by less than $1 \%$ relative to the baseline

Table 2 Percentage reductions in direct capital damage in the scenario run relative to the original model

\begin{tabular}{llll}
\hline$p_{i}$ multiplied by & \multicolumn{4}{l}{$\Delta_{\mathrm{si}, i}$ multiplied by } \\
\cline { 2 - 4 } & 1 & 10 & 100 \\
\hline 1 & 0.00 & 0.07 & 3.23 \\
10 & 0.01 & 0.07 & 3.25 \\
100 & 0.03 & 0.09 & 3.40 \\
1000 & 0.07 & 3.40 & 4.81 \\
\hline
\end{tabular}

Table 3 Percentage reductions in casualties in the scenario run relative to the original model

\begin{tabular}{llll}
\hline$p_{i}$ multiplied by & \multicolumn{4}{l}{$\Delta_{\mathrm{si}, i}$ multiplied by } \\
\cline { 2 - 4 } & 1 & 10 & 100 \\
\hline 1 & 0.02 & 0.02 & 0.09 \\
10 & 0.02 & 0.02 & 0.09 \\
100 & 0.02 & 0.02 & 0.09 \\
1000 & 0.02 & 0.09 & 0.12 \\
\hline
\end{tabular}

scenario. In scenarios where $\Delta_{\mathrm{S}, i}$ increases by a factor of 100, capital damage is reduced by between 3 and $5 \%$. However, the reductions in casualties are almost identical across all scenarios.

\section{Indirect and long-term effects: welfare losses and tax} revenue

Welfare losses, calculated as equivalent variation (Hicks 1943), over the time span 2007-2025 are depicted in Fig. 3. Here equivalent variation refers to welfare losses as a percentage of household's yearly income. The time period covers both the ex-ante period as well as long-term ex-post. In a given year (horizontal axis), the isolines show the reduction in welfare as $p_{i}$ increases. Movements along the vertical axis thus show how impacts vary with different probabilities of flooding, while movements along the horizontal axis illustrate how impacts develop over time. The left panel shows results from scenarios where $\Delta_{\mathrm{Si}, i}$ in Eq. 6 is held at its current level, the centre panel shows results from scenarios where $\Delta_{\mathrm{Si}, i}$ increases by a factor of 10 , and the right panel shows results from scenarios where $\Delta_{\mathrm{Si}, i}$ increases by a factor of 100 .

The left panel, which shows results from scenarios where damage is kept constant, suggests that welfare losses due to the modified investment behaviour are minor. Before the flood, welfare losses amount to maximum $0.01 \%$ of household income. After the flood, the decrease in welfare corresponds to maximum $0.08 \%$ of household income. However, the figure also suggests welfare losses are almost entirely due to the flood. Welfare losses are substantially larger in scenarios where $\Delta_{\mathrm{Si}, i}$ increase by a factor of 10 (centre panel), but the increase in welfare losses is not proportional to the increase in $\Delta_{\mathrm{Si}, i}$. Welfare losses before 2016 are maximum $0.05 \%$ of household income.

The centre panel shows that changes in probability have some effect on welfare losses: for the current level of probability, there are welfare decreases by about $0.1 \%$ and for cases where probability increases by a factor of 100 welfare decreases by more than $0.25 \%$. The right 


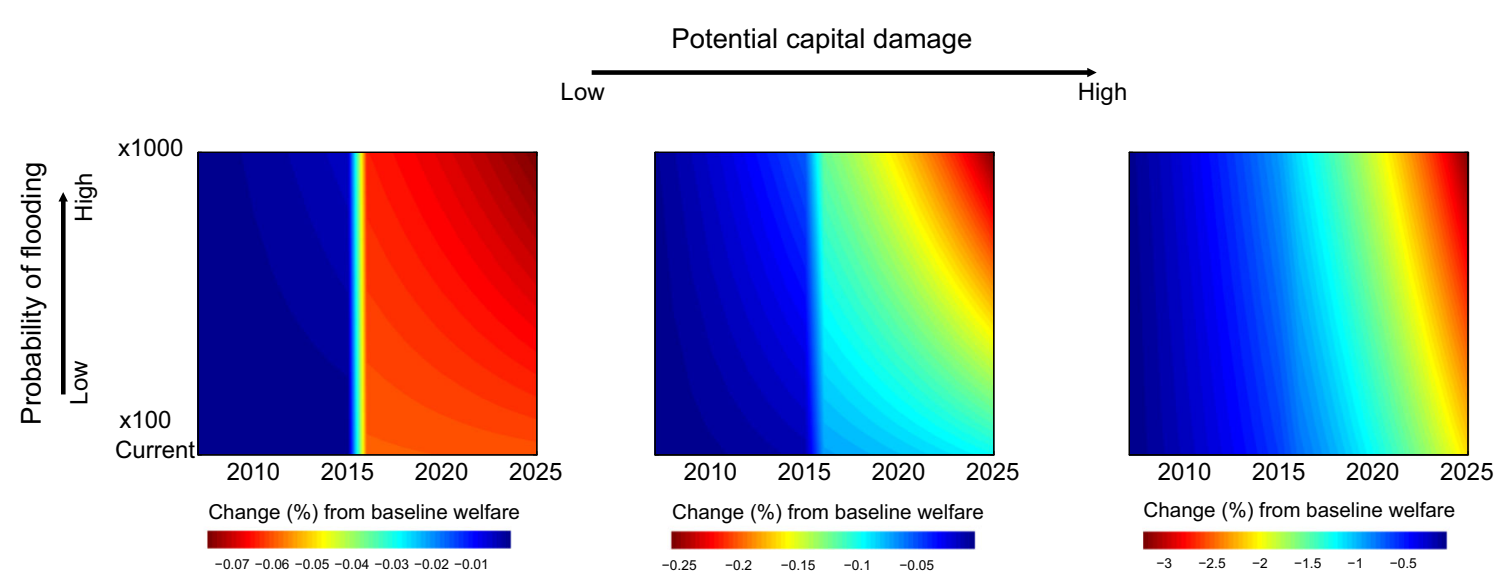

Fig. 3 Changes in household welfare in the large Rotterdam area across scenarios. The vertical axis shows $p_{i}$, while the horizontal axis shows year. The left panel shows results from scenarios where $\Delta_{S i, i}$ in Eq. 6 is held at its current level, the centre panel shows results from scenarios where $\Delta_{\mathrm{Si}, i}$ increases by a factor of 10 , and the right panel shows results from scenarios where $\Delta_{\mathrm{Si}, i}$ is increased by a factor of 100 panel, which shows results from scenarios where $\Delta_{\mathrm{Si}, i}$ increases by a factor of 100, shows a further decrease in welfare, amounting to around $1 \%$ of income before the flood, reaching a maximum of above $3 \%$ of income around 2025. The right panel suggests that welfare losses are almost entirely driven by the modified investment behaviour. Losses accelerate over time and are mainly driven by $\Delta_{\mathrm{Si}, i}$ (although flatter isolines towards the end of the time interval indicate that differences in probabilities become more important over time). The indirect effects of a flood have negative impacts on the governments' fiscal position in the sense that a drop in production reduces tax income. However, as shown above, the modified investment behaviour diverts production away from the region of Rotterdam, reducing the impact of a flood and, as a consequence, the indirect effects. This is illustrated in Fig. 4 where the left panel shows results for scenarios where damage in Eq. 6 is kept at its current level. The modified investment behaviour leads to a slight increase in tax revenue before the flood (around 1 $\%$ higher than baseline tax revenue by 2015). The flood leads to an immediate drop in tax revenue in all scenarios. Interestingly, for scenarios where probability increases by a factor of 10 or 100 , the increasing isolines suggest that the flood has the effect of setting the economy on to a negative growth path with declining tax revenues over time. The middle and right panel of Fig. 4 suggest that diversion of investment away from the region of Rotterdam has in fact a positive effect on tax revenues. This suggests that the modified investment behaviour and the ensuing outflow of productive capital from the region of Rotterdam limits the impact of a flood on public finances.

\section{Discussion}

The possibility of future increases in flood risk has intensified the debate on the roles and responsibilities of public and private sector agents in flood risk management. The discussion is particularly relevant for our case study-the large Rotterdam area in the Netherlands. Traditionally, Dutch flood risk management has focused almost entirely on prevention and public ex-post loss compensation. This strategy can be explained by high concentration of population and economic assets in flood-prone areas, leading to covariate risk in the case of a flood disaster (Mechler and Bouwer 2014). Large and quasi-irreversible investment costs and the public good features of flood protection justify an important role of the Dutch government in flood risk management in the Netherlands (Fankhauser et al. 1999). Attempts of introducing private property insurance are complicated by high transaction costs, uncertainties related to risk assessment and limited markets for risk-sharing products (Froot 2001). It is, however, increasingly argued that the traditional approach should be complemented with measures limiting the consequences in case of a flood (Kabat et al. 2005). Answering calls for a more integrated approach, the Dutch government has made efforts in incorporating, for example, spatial planning measures in flood risk management policies (van den Hurk et al. 2014; Min I \& M 2014). Crucially, the new approach entails a partial shift in the allocation of risk, where private sector agents to some extent are responsible for covering their own risk. However, as the recent rejection of mandatory flood insurance for home owners has shown, the introduction of market-based instruments is likely to face challenges. In this paper, we have attempted 


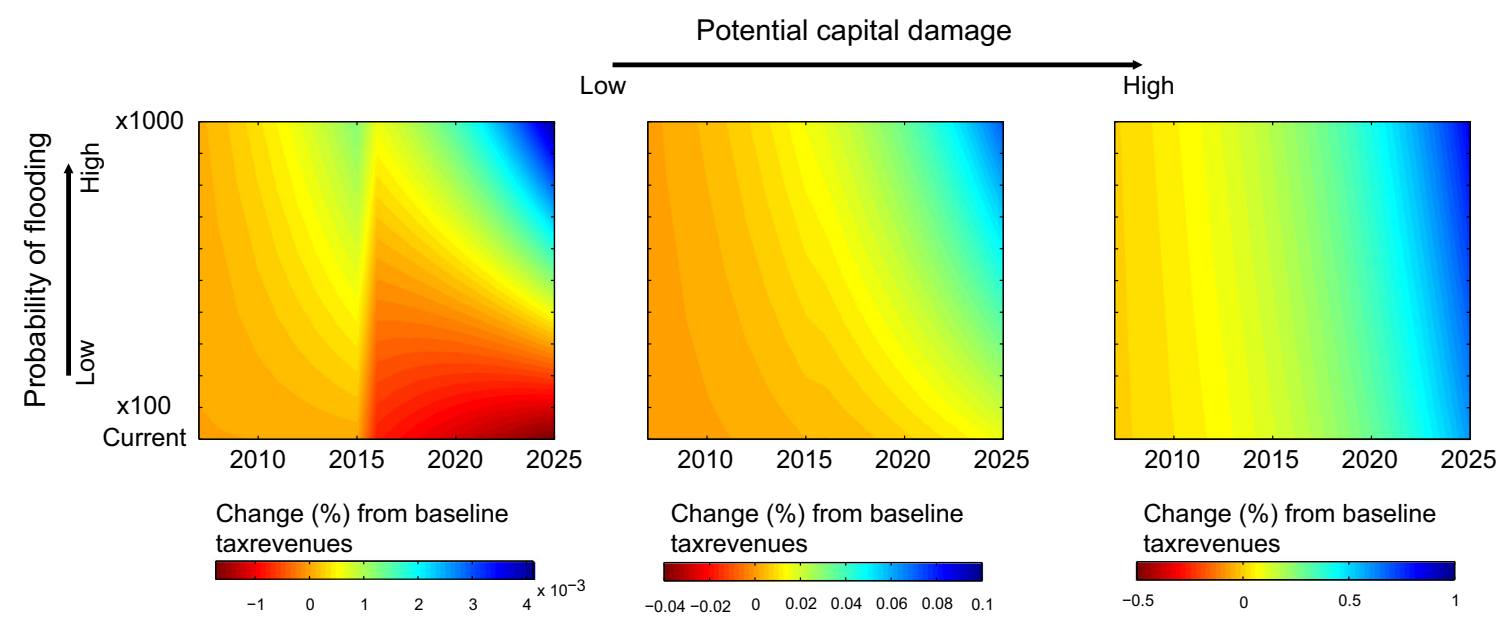

Fig. 4 Changes in tax revenues of the government across scenarios. The vertical axis shows $p_{i}$, while the horizontal axis shows year. The left panel shows results from scenarios where $\Delta_{\mathrm{Si}, i}$ in Eq. 6 is held at its current level, the centre panel shows results from scenarios where

to inform the debate by studying macroeconomic implications of a possible incentive effect from increased risk awareness.

The goal of this article was to investigate the long-term economic and welfare effects if risk-averse investors in the Netherlands took flood risk into account in their investment decisions. By increasing the values of the key parameters probability of flooding and potential capital damage, we shed some light on the potential investor responses to two aspects of flood risk and on the ensuing macroeconomic effects. More specifically, we analysed impacts on production, on population and on household welfare in the large Rotterdam area when risk-averse investors started worrying about downside risk in the region.

Our results suggest that combinations of increases in probability and capital damage can cause investors to divert investments away from the large Rotterdam area. Yet, the decline in investment has a dual impact. On the one hand, there is a reduction in productive capital in the region, reducing capital damage in case of a flood by as much as $5 \%$. The reductions in productive capital also reduce the impact from a flood on tax revenues. On the other hand, the decrease in economic activities also leads to an increase in unemployment and prices of consumption goods, causing welfare losses among households in the large Rotterdam. According to our results, these welfare losses can amount to more than $3 \%$ of yearly household income. Overall, although potential disaster losses can be reduced, it is questionable whether diversion of investments away from risky areas is desirable due to the negative side effects. This resonates with conclusions drawn in other studies (Linnerooth-Bayer and Amendola 2000; Ligtvoet et al. 2009).

Turning to the sensitivity of our results to increases in key parameters, our simulation exercises suggest that
$\Delta_{\mathrm{Si}, i}$ increases by a factor of 10 , and the right panel shows results from scenarios where $\Delta_{\mathrm{Si}, i}$ increases by a factor of 100

investment decisions are particularly sensitive to increased capital damage (higher $\Delta_{\mathrm{Si}, i}$ ). If the potential capital damage increases to close to $100 \%$, anything else than very high levels of protection is likely to cause large decreases in investments. This reflects a frequently raised concern in the current Dutch policy debate: high and increasing exposure justifies very high safety levels. Projected future increases in the concentration of economic activity in vulnerable areas such as the region of Rotterdam provide arguments for increasing the protection in these areas (Kind 2014).

The point of departure for our analysis is that, while there is a good understanding about flood risk in the Netherlands, risk is currently of limited importance for household-level adaptation. This is in line with conclusions drawn in empirical studies that argue that flood risk is a relatively minor concern for people in the Netherlands (Terpstra et al. 2009). Indeed, international experience shows that in the absence or a long time after an event, risk is likely to have a limited direct impact on household decision making (see Slovic 1987). For example, Kunreuther and Pauly (2006) argue that both probabilities and potential government assistance are of limited importance in household decisions on whether or not to buy insurance. Most importantly, risk may play a limited role in households location decision (Hunter 2005). Studies examining housing market impacts of floods show that risk perceptions are systematically increased by concrete events, yet only temporarily so. Such studies find that disaster events such as floods lead to a temporary housing price difference between risky and non-risky areas (e.g. Bin and Landry 2013; Atreya et al. 2013).

Overall, lack of actionable risk perceptions and strong incentives may lead to increasing exposure over time, 
meriting considerations regarding policy-induced reallocation of risk from the public to the private sector. We have analysed a situation where risk is directly relevant only for investors, while households are indirectly affected through supply-side adjustments and ensuing price effects. However, as our results suggest, the indirect effects, reflected as lower production and increased unemployment in areas at risk, do not necessarily provide strong enough signals for households to relocate. This is in line with results from other studies (Glaeser and Gyourko 2005; Vigdor 2008). The negative welfare effects associated with the reallocation of risk voice the equity concerns raised by LinneroothBayer and Amendola (2000).

It is argued that the current policy regime in the Netherlands provides little incentives for individual adaptation (Botzen and van den Bergh 2008; Aerts and Botzen 2011; Filatova 2014). Our model results suggest that a partial reallocation of risk can provide incentives for individual adaptation. On the one hand, our results suggest that the direct capital damage from a flood can be reduced by diverting investments away from areas at risk. Provision of information about hazard as well as information about the effectiveness of individual adaptation measures could help private sector agents in making decisions on their own exposure to flood risk. On the other hand, ensuring the public good characteristics of protection is an important goal for policy makers: publicly financed prevention can help ensuring that safety does not become a good primarily enjoyed by the privileged.

In order to make the analysis clear and the model tractable, we have relied on a number of simplifying assumptions. Firstly, as a country-level analysis would require additional data on flood damage from other regions, we have limited our analysis to the large Rotterdam area. Secondly, we have followed the convention of modelling a representative regional household who does not react to the level or changes in risk. This allows us to observe changes in average values, but we are unable to provide detailed analyses of changes in the socio-economic composition of a region. We leave these open questions for future research.

\begin{abstract}
Acknowledgments We are grateful to two anonymous reviewers and editor Christopher Reyer for very useful and constructive comments. We would also like to thank the participants of the IIASA Young Scientist Summer Programme 2013 and IIASA staff for comments on an earlier version of this paper. Financial support from The Research Council of Norway, the Dutch Knowledge for Climate Research Programme and the European Commission funded ENHANCE project (grant agreement number 308438) is gratefully acknowledged.
\end{abstract}

Open Access This article is distributed under the terms of the Creative Commons Attribution License which permits any use, distribution, and reproduction in any medium, provided the original author(s) and the source are credited.

\section{References}

Aakre S, Banaszak I, Mechler R, Ruebbelke D, Wreford A, Kalirai H (2010) Financial adaptation to disaster risk in the European Union. Mitig Adapt Strat Glob Change 15(7):721-736. doi:10. 1007/s11027-010-9232-3

Aerts JCJH, Botzen WJW (2011) Climate change impacts on pricing long-term flood insurance: A comprehensive study for the Netherlands. Global Environ Change 21(3):1045-1060. doi:10. 1016/j.gloenvcha.2011.04.005

Atreya A, Ferreira S, Kriesel W (2013) Forgetting the flood? An analysis of the flood risk discount over time. Land Econ 89(4):577-596

Baker SR, Bloom N (2013) Does uncertainty reduce growth? Using disasters as natural experiments. Tech. rep. National Bureau of Economic Research

Balvers R, Du D, Zhao X (2009) What do financial markets reveal about global warming? Working paper, Department of Economics. West Virginia University

Barro RJ (2013) Environmental protection, rare disasters, and discount rates. NBER Working Papers 19258. National Bureau of Economic Research Inc

Bin O, Landry CE (2013) Changes in implicit flood risk premiums: empirical evidence from the housing market. J Environ Econ Manag 65(3):361-376. doi:10.1016/j.jeem.2012.12.002

Botzen WJW (2013) Managing extreme climate change risks through insurance. Cambridge University Press, Cambridge

Botzen WJW, van den Bergh J (2012) Risk attitudes to low-probability climate change risks: WTP for flood insurance. J Econ Behav Organ 82(1):151-166. doi:10.1016/j.jebo.2012.01.005

Botzen WJW, van den Bergh JCJM (2008) Insurance against climate change and flooding in the Netherlands: present, future, and comparison with other countries. Risk Anal 28(2):413-426. doi:10.1111/j.1539-6924.2008.01035.x

Bouwer LM, Vellinga P (2007) On the flood risk in the Netherlands. In: Begum S, Stive M, Hall J (eds) Flood risk management in Europe, advances in natural and technological hazards research, vol 25. Springer, Dordrecht, pp 469-484

Daniel VE, Florax RJGM, Rietveld P (2009) Floods and residential property values: a hedonic price analysis for the Netherlands. Built Environ 35(4):563-576

de Bruijn KM, der Doef M (2011) Gevolgen van overstromingen. Informatie ten behoeve van het project waterveiligheid $21 \mathrm{e}$ eeuw, Deltares, Delft

de Moel H, Aerts JCJH, Koomen E (2011) Development of flood exposure in the Netherlands during the 20th and 21st century. Global Environ Chang 21(2):620-627. doi:10.1016/j.gloenvcha. 2010.12.005

de Moel H, van Vliet M, Aerts J (2014) Evaluating the effect of flood damage-reducing measures: a case study of the unembanked area of Rotterdam, the Netherlands. Reg Environ Change 14(3):895-908. doi:10.1007/s10113-013-0420-z

Fankhauser S, Smith JB, Tol RSJ (1999) Weathering climate change: some simple rules to guide adaptation decisions. Ecol Econ 30(1):67-78. doi:10.1016/S0921-8009(98)00117-7

Filatova T (2014) Market-based instruments for flood risk management: a review of theory, practice and perspectives for climate adaptation policy. Environ Sci Policy 37:227-242. doi:10.1016/j. envsci.2013.09.005

Froot KA (2001) The market for catastrophe risk: a clinical examination. J Financ Econ 60(23):529-571. doi:10.1016/ S0304-405X(01)00052-6

Fujita M, Thisse JF (1996) Economics of agglomeration. J Jpn Int Econ 10(4):339-378 
Glaeser EL, Gyourko J (2005) Urban decline and durable housing. J Polit Econ 113(2):345-375

Hallegatte $S$ (2008) An adaptive regional input-output model and its application to the assessment of the economic cost of Katrina. Risk Anal 28(3):779-799. doi:10.1111/j.1539-6924.2008.01046.x

Hallegatte S (2011) How economic growth and rational decisions can make disaster losses grow faster than wealth. Policy Research Working Paper Series 5617, The World Bank

Hicks JR (1943) The four consumer's surpluses. Rev Econ Stud 11(1):31-41

Hunter LM (2005) Migration and environmental hazards. Popul Environ 26(4):273-302

Husby TG, de Groot HLF, Hofkes MW, Dröes MI (2014) Do floods have permanent effects? Evidence from the Netherlands. J Reg Sci 54(3):355-377. doi:10.1111/jors.12112

Ivanova O, Heyndrickx C, Spitaels K, Tavasszy L, Manshanden W, Snelder M, Koops O (2007) RAEM: version 3.0. First report, Transport \& Mobility Leuwen

Jongman B, Koks EE, Husby TG, Ward PJ (2014) Increasing flood exposure in the Netherlands: implications for risk financing. Nat Hazard Earth Sys Sci 14(5):1245-1255. doi:10.5194/nhess-141245-2014

Jonkhoff W, Koops O, van der Krogt RAA, Oude Essik GHP, Rietveld E (2008) Economische effecten van klimaatverandering. Overstroming en verzilting in scenario's, modellen en cases. Tno-rapport, TNO Bouw en Ondergrond

Kabat P, van Vierssen W, Veraart J, Vellinga P, Aerts J (2005) Climate proofing the Netherlands. Nature 438(7066):283

Kind J (2014) Economically efficient flood protection standards for the Netherlands. J Flood Risk Manag 7(2):103-117. doi:10.1111/ jfr3.12026

Kok M, Huizinga HJ, Vrouwenvelder ACWM, Barendregt A (2005) Standaardmethode 2004 Schade en Slachtoffers als gevolg van overstromingen. Dww-2005-005, RWS Dienst Weg-en Waterbouwkunde

Kousky C, Luttmer EFP, Zeckhauser RJ (2006) Private investment and government protection. J Risk Uncertain 33(1):73-100

Krugman P (1991) Increasing returns and economic geography. J Polit Econ 99(3):483-99

Kunreuther H, Pauly M (2006) Rules rather than discretion: lessons from Hurricane Katrina. J Risk Uncertain 33(1-2):101-116. doi:10.1007/s11166-006-0173-x

Ligtvoet W, Knoop J, Strengers B, Bouwman A (2009) Flood protection in the Netherlands: framing long-term challenges and options for a climate-resilient delta. Policy studies, Netherlands Environmental Assessment Agency, Dordrecht

Linnerooth-Bayer J, Amendola A (2000) Global change, natural disasters and loss-sharing: issues of efficiency and equity. Geneva Pap R I-Iss P 25(2):203-219

Linnerooth-Bayer J, Hochrainer-Stigler S (2014) Financial instruments for disaster risk management and climate change adaptation. Clim Change 1-16: doi:10.1007/s10584-013-1035-6
Markowitz H (1959) Portfolio selection: efficient diversification of investments. Wiley, New York

Mechler R (2004) Natural disaster risk management and financing disaster losses in developing countries. PhD thesis, Karlsruher Reihe II, Risikoforschung und Versicherungsmanagement

Mechler R (2013) Modeling aggregate economic risk: An introduction. In: Integrated Catastrophe Risk Modeling, Springer, pp 95-102

Mechler R, Bouwer LM (2014) Understanding trends and projections of disaster losses and climate change: Is vulnerability the missing link? Clim Change 1-13: doi:10.1007/s10584-0141141-0

Mechler R, Bouwer LM, Linnerooth-Bayer J, Hochrainer-Stigler S, Aerts JCJH, Surminski S, Williges K (2014) Managing unnatural disaster risk from climate extremes. Nat Clim Change 4(4):235-237

Merz B, Kreibich H, Schwarze R, Thieken A (2010) Assessment of economic flood damage. Nat Hazard Earth Syst 10(8):1697-1724

Min I \& M (2009) National Water Plan. Ministry of Infrastructure and the Environment, the Hague

Min I \& M (2014) Synthesedocument deelprogramma Veiligheid. Backgroundreport deltaprogramma 2015, Ministry of Infrastructure and the Environment, the Hague

Okuyama Y (2008) Critical review of methodologies on disaster impacts estimation. Background paper for EDRR report

Rose A (2004) Economic principles, issues and research priorities in hazard loss estimation. In: Chang S (ed) Modeling the spatial economic impacts of natural hazards. Springer, Dordrecht, pp 119-142

Slovic P (1987) Perception of risk. Science 236(4799):280-285

Terpstra T, Lindell MK, Gutteling JM (2009) Does communicating (flood) risk affect (flood) risk perceptions? Results of a quasiexperimental study. Risk Anal 29(8):1141-1155. doi:10.1111/j. 1539-6924.2009.01252.x

Thissen M (2005) RAEM : Regional applied general equilibrium model for the Netherlands. In: A survey of spatial economic planning models in the Netherlands. Theory, application and evaluation, NAi Publishers, Rotterdam Netherlands Institute for Spatial Research (rpb), Den Haag

van den Hurk M, Mastenbroek E, Meijerink S (2014) Water safety and spatial development: an institutional comparison between the United Kingdom and the Netherlands. Land Use Policy 36:416-426. doi:10.1016/j.landusepol.2013.09.017

Veraart J, van Nieuwaal K, Driessen P, Kabat P (2014) From climate research to climate compatible development: experiences and progress in the Netherlands. Reg Environ Change 14(3):851-863. doi:10.1007/s10113-013-0567-7

Vigdor J (2008) The economic aftermath of Hurricane Katrina. J Econ Perspect 22(4):135-54. doi:10.1257/jep.22.4.135 